\title{
People's Recycling Behavior in Cape Town-South Africa
}

\author{
RO Anyasi'; HI Atagana², \\ Department of Environmental Science ${ }^{1}$ \\ Department of Life and Consumer Sciences ${ }^{2}$ \\ University of South Africa \\ eanyasro@unisa.ac.za \\ atagahi@unisa.ac.za \\ +27123376194
}

\begin{abstract}
To understand the interest of people over any activity, it is important such attitude is surveyed. This paper analysed the actions of households towards recycling as it forms a sustainable means of waste management. This is to establish the impact of such behaviour in limiting the success of recycling practise. 400 randomly selected households in the suburb of Upper Claremont in the city of Cape Town, South Africa, were used in the study. Data was collected using a structured questionnaire targeted at the head or breadwinner of each household in the area. Analysis of the results showed that $67.3 \%$ of the sampled households do not recycle waste, meaning that more effort should be geared towards awareness creation for people to understand the benefits of recycling. There was lack of basic recycling education and guidance coupled with inadequacy in infrastructure and services which negatively deters the interest for recycling. Pearson correlation analysis showed a significant and positive relationship $(r=0.89, p=0.003)$ (significant level at $\mathrm{p}<$ 0.05 ) between waste management interests and the recycling ability of individual households. SWOT analysis shows increase in environmental awareness as the strength, insufficiently developed recycling collection infrastructure as weakness, development of convenient recycling collection infrastructures and incentives for example tax reduction as opportunities, while threats is that recycling may not be financially rewarding in short run. It was recommended that government should install more convenient recycling depots, as well as raising environmental awareness campaigns.
\end{abstract}

Keywords: Household Waste management, People's behaviour, Recycling, SWOT analysis, South Africa

\section{Introduction}

Solid waste generation is one of the most critical issues effecting the environment today. The rate of urbanisation along with quests for a higher income level has been directly linked to an increase in waste generation in households [1]. Recycling is the best way to address the waste issues as it slows down the production of waste which ultimately is deposited into landfills around the globe [2]. Recycling ensures a cleaner environment with less pollution, helping to sustain the environment for future generations and reduce greenhouse gas emissions. Recycling also conserves the environment by saving energy, preserving resources, protecting wildlife and saving millions of trees [3,4].

The act of recycling is a process whereby wastes are collected and processed into new products instead of disposing them. Recyclable materials include plastic, glass, paper, metals (aluminium), electronics etc. as can be found in Table 1 [3]. Recycling does not only benefit the environment, but the community as well by providing employment opportunities. In a country such as South Africa with unemployment rate of $23.9 \%$ the mentioned benefits above forms an important benefit [5]. According to the City of Cape Town's Waste Review (2016), Cape Town's landfills are running dangerously into short of space. Frightening statistics were revealed from the results of two surveys conducted in 2010 by the South African Council for Scientific and Industrial Research (CSIR); which shows that only 3.3\% of South Africa's urban population recycles household waste [6,7]. The same study concluded that out of approximately 19 million tons of municipal waste generated, about $25 \%$ were mainline recyclables such as paper, glass, plastic and tins. Two-thirds of the more than 2000 urban South African households surveyed do not know where to dispose of household recyclables, and the majority of participants do not know how to recycle or what can/can't be recycled $[8,9]$.

In furtherance to the 2010 surveys, there was an overall negative attitude towards recycling. Reasons for not recycling according to the survey were identified and included; lack of time, lack of interest, lack of space, people lacking the knowledge of what is/is not recyclable, as well as the lack of convenient recycling depots [10,11]. It was discovered that South Africans would possibly begin to recycle if they understand what it means and if it is made more convenient 
[12]. Solid waste management is one of the most critical environmental problems facing our planet today and leads to environmental hazards such as infectious disease, environmental degradation, water and soil pollution, greenhouse gas emissions and negative impacts on the quality of human life [13]. Developing countries such as South Africa are worse affected by these issues. This problem highlights the urgency for responsible waste management at grass roots level starting at the home1. It is essential that every household is able to manage their own waste in the most environmentally sustainable way possible which includes making recycling practices part of the everyday household routine.

According to Mtutu and Thondhlana [14], one of the root causes for environmental challenges such as global warming and water shortages, are deep-rooted in human practices and especially in human behavioural patterns. It is therefore necessary to discover why exactly households do not recycle and what can be done to improve statistics and encourage households to responsibly manage waste. The 2014 Waste amendment Act of South Africa identified the waste sector as having significant potential for job creation and contributing to the macro economy of South Africa and other countries in the region. But this will be far-fetched when one of the important sectors of waste management is not optimized as a result of the minimal information available to people on recycling.

There have been numerous studies conducted around the world concerning household recycling behaviour aimed at using the information to improve and encourage pro-recycling behaviour; each study is specific to a geographical area with various demographic and socio economic factors [1,15-16]. In South Africa however, most studies on the behaviour of people towards recycling has only addressed individuals in establishments [14]. There has not been any study that identifies collective behaviour of households in the community, hence the intention of this so as provide strategies for appropriate waste management improvement. The aim of the study therefore is to identify these recycling behaviours of households in Upper Claremont, Cape Town, so as to be able to suggest on ways of improving household waste management.

\section{Methodology}

The study was conducted in the suburb Upper Claremont, Cape Town, Western Cape Province. Upper Claremont is comprised of residential property only and forms part of the greater suburb of Claremont. According to the City of Cape Town census, presented by Statistics South Africa [5], Claremont has a population of 17 198, and 95\% of the labour force (age 15-64) is employed. 89\% of those aged 20 years and older have completed Grade 12 or higher and $99.5 \%$ of households live in formal dwellings ${ }^{5,14}$. The geographic area of Upper Claremont is governed by the City of Cape Town Metropolitan Municipality and the centre of Upper Claremont's geographical coordinates is 33.987765 S, $18.455907 \mathrm{E}$, with the total surface area of 827, $600.64 \mathrm{~m}^{2}$ (Google Maps 2016).

\subsection{Research Design}

A quantitative research design by the means of a questionnaire/survey was employed

\subsection{Calculation of Sample Size}

The area of Upper Claremont has a population of 2866 inhabitants and on average 3 people live in each household. The sample size of a population of 2866 equals 496 people calculated by a sample calculator (Creative Research Systems 2012), as reported by Pakpour et al. ${ }^{16}$. Considering that the average household size is 3 it is calculated that any number from 165 questionnaires will need to be distributed in order to reflect a true understanding of this populations recycling behaviour so as to generalize.

Calculation:

$$
496 / 3=165
$$

(Eqn. 1)

\subsection{Questionnaire Design}

The survey was conducted between April and September 2016. The questionnaire consisted of 17 questions partitioned into 6 sections. The questions incorporated both predefined and open designs considering basic information about a respondent (including age, gender, level of education, employment status, and household composition), attitude towards recycling, material being recycled, Reason for not recycling, and impacts of the municipality. From the results of the survey, strengths, weaknesses, opportunities and threats (SWOT) of waste recycling amongst households of the suburb were evaluated. 


\section{Results}

Of nearly 600 houses approached for this study, 100 households declined, but 500 questionnaires were distributed and eventually 400 were answered and returned indicating about $80 \%$. Households which refused to partake in the study had either said that they were too busy to answer, the owners of the household were not home, or were simply not interest in responding once hearing that it was a questionnaire to assess recycling behaviour. This from the beginning of the study gave a view of how people are disinterested in matters regarding recycling.

The first question of the survey asked participants out right if their household recycled all, if not some, of their waste. It was discovered that $67.3 \%$ of households do not recycle any of their household waste, highlighting the need for recommendations to be made to increase recycling behaviour in the Upper Claremont area. $67.9 \%$ of the total respondents were females, and $27.3 \%$ are housewives. This statistic immediately indicates how many women in this area are stay at home wives and have a great influence on whether the household will/will not recycle. The majority of respondents were over the age of 46 years old with $40 \%$ being between the ages of 46 and 60, and $38.2 \%$ being over 65 years old. Recycling behaviour increased with an increase in age; with respondents over the age of 65 and retired being more likely to recycle. This could either be because of an increase in the amount of time available or an increase in desire to conserve the environment for future generations. There does not seem to be a link between educational level and recycling behaviour as many respondents with post graduate degrees do not recycle.

There is a very low unemployment rate in Upper Claremont with only $2.4 \%$ people indicating that they are unemployed. $42.8 \%$ of respondents indicated that they were employed, $27.3 \%$ said that they were house wives and $28.5 \%$ were retired. The majority of respondents $(75.8 \%)$ are married as well as $66.1 \%$ of households having children. This indicates that many households in Upper Claremont are families. Considering that children live in $66.1 \%$ of houses in Upper Claremont this highlights a great opportunity for recycling knowledge to be taught in schools. Children can influence household recycling behaviour by learning the importance of recycling at school as well as basic recycling knowledge which they can teach their parents and practice at home. If information about recycling cannot be included in the school curriculum then a recycling club could be a powerful tool in promoting positive recycling behaviour. A fun way to get children to recycle is by hosting a recycling competition between local schools where the school who collects the most recyclables wins a prize.

The following table represents all the demographic information captured from questionnaires as well as the percentage of the 165 questionnaires distributed.

Table 1- Demographic characteristics of questionnaire respondents

\begin{tabular}{|l|l|}
\hline$\underline{\text { Variables }}$ & $\underline{\mathbf{N}=\mathbf{4 0 0}}$ \\
\hline$\underline{\text { Gender }}$ & \\
\hline Male & $128(32.1 \%)$ \\
\hline Female & $272(67.9 \%)$ \\
\hline$\underline{\text { Age }}$ & \\
\hline $18-30$ & $22(5.5 \%)$ \\
\hline $31-45$ & $66(16.4 \%)$ \\
\hline $46-60$ & $160(40 \%)$ \\
\hline $60+$ & $152(38.1 \%)$ \\
\hline Highest level of education & \\
\hline High School & $189(47.3 \%)$ \\
\hline Under Graduate degree & $133(33.3 \%)$ \\
\hline Post Graduate & $78(19.4 \%)$ \\
\hline Employment status & \\
\hline Unemployed & $10(2.4 \%)$ \\
\hline
\end{tabular}




\begin{tabular}{|l|l|}
\hline Employed & $171(42.8 \%)$ \\
\hline House wife & $105(26.3 \%)$ \\
\hline Retired & $114(28.5 \%)$ \\
\hline Household composition & \\
\hline Single & $39(9.7 \%)$ \\
\hline Married & $303(75.8 \%)$ \\
\hline Widow/Widower & $58(14.5 \%)$ \\
\hline Children in household & \\
\hline Yes & $264(66.1 \%)$ \\
\hline No & $136(33.9 \%)$ \\
\hline
\end{tabular}

There was a strong correlation between environmental concern and a sense of personal responsibility with household recycling behaviour. A total of $55.2 \%$ of non-recyclers disagreed or strongly disagreed that if their single household recycled its waste, that this would not make a difference to a global waste production issue. This indicates a serious lack of awareness to environmental issues as well as ignorance. Out of the respondents who do recycle their waste, $100 \%$ of them felt that they have a personal responsibility to sustain our natural environment, as well as $93.4 \%$ of recyclers felt that every household should recycle. This indicates that a sense of personal responsibility is an important factor in recycling behaviour. This finding suggests that strategies which promote a sense of personal responsibility and moral obligation would be powerful in changing people's perceptions on how they can be making a difference to the environment.

According to Bortoleto at $\mathrm{al}^{12}$, one reason for the steady increase in waste generation globally is due to the lack of participation by individuals in household waste reduction behaviours. If everybody had the attitude of "An individual won't make a difference globally" then tackling a global waste issue will be impossible. This calls for a change in perception which can be realised through educating people about the importance of recycling and how each household will indeed make a difference to a global issue. The result of this study is not in agreement with the postulates of Kim and Choi (2005) that reported the relationship between collectiveness and pro-environmental choices. A very low $33.7 \%$ of respondents who indicated that they do recycle some, if not all of their household waste were asked which materials they recycle. The most popular material to recycle is plastic, and the least popular materials are electronics. The following graph portrays which materials are mostly recycled in the household. 


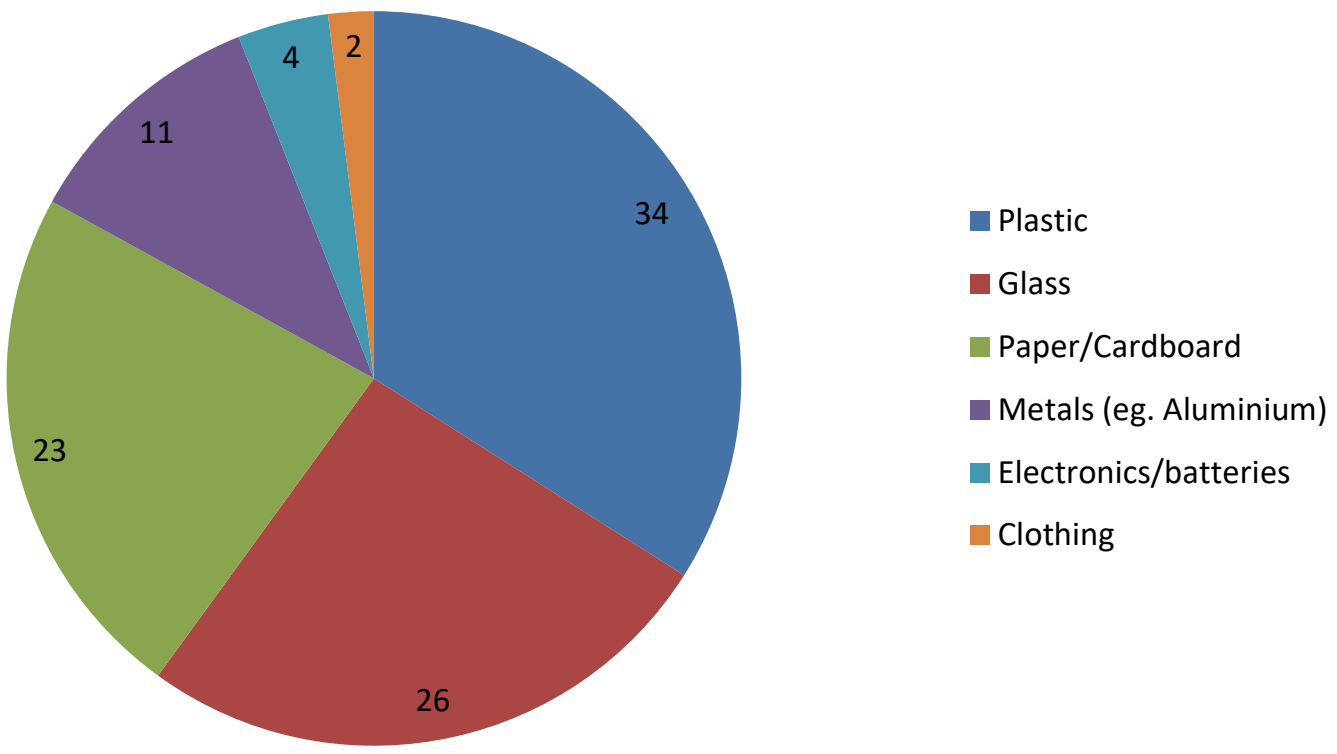

Figure 1: Pie graph representing types of materials recycled by households of Upper Claremont, Cape Town.

It was important to assess how these recyclers dispose of their recycling in an area that lack a convenient pick up service provided for by the municipality. Most of the respondents chose to recycle even in the face of inconvenience and time constraint. $21.8 \%$ of recyclers make use of a private recycling collection service, $44.8 \%$ drop off their recycling at a recycling depot such as San Souci High School, 29.1\% support the Oasis recycling association by either having their recyclables collected by them or by dropping off recycling at the association depot in the neighbouring suburb of Lansdowne, and $4.1 \%$ indicated that they use 'other' disposal methods.

Out of the $67.3 \%$ of respondents who indicated that they do not recycle, $47.3 \%$ of them felt that they want to recycle, but that limiting factors are prohibiting them from doing so such as the constraints of time, space, recycling knowledge, and convenient recycling disposal services. This indicates that a number of households would indeed recycle if it was made to be more convenient for them. The study of Robinson and $\operatorname{Read}^{4}$, indicated that time and space unavailability as well as disinterest to recycling all leads to poor recycling habits. The majority of non-recyclers identified that all of these factors hinder their ability to recycle. The most influential factor is that recycling is an inconvenience due to a lack of convenient recycling services, as well as a lack of basic recycling knowledge. Lack of recycling knowledge greatly hinders recycling efforts. Households need to be educated on the benefits of recycling to the environment, what materials are/are not recyclable, how to separate recycling, etc. if we are to improve recycling behaviour. This result is in agreement with the work of Pakpour et al. [16], which reported on the negative impact of some of the limiting factors on waste management.

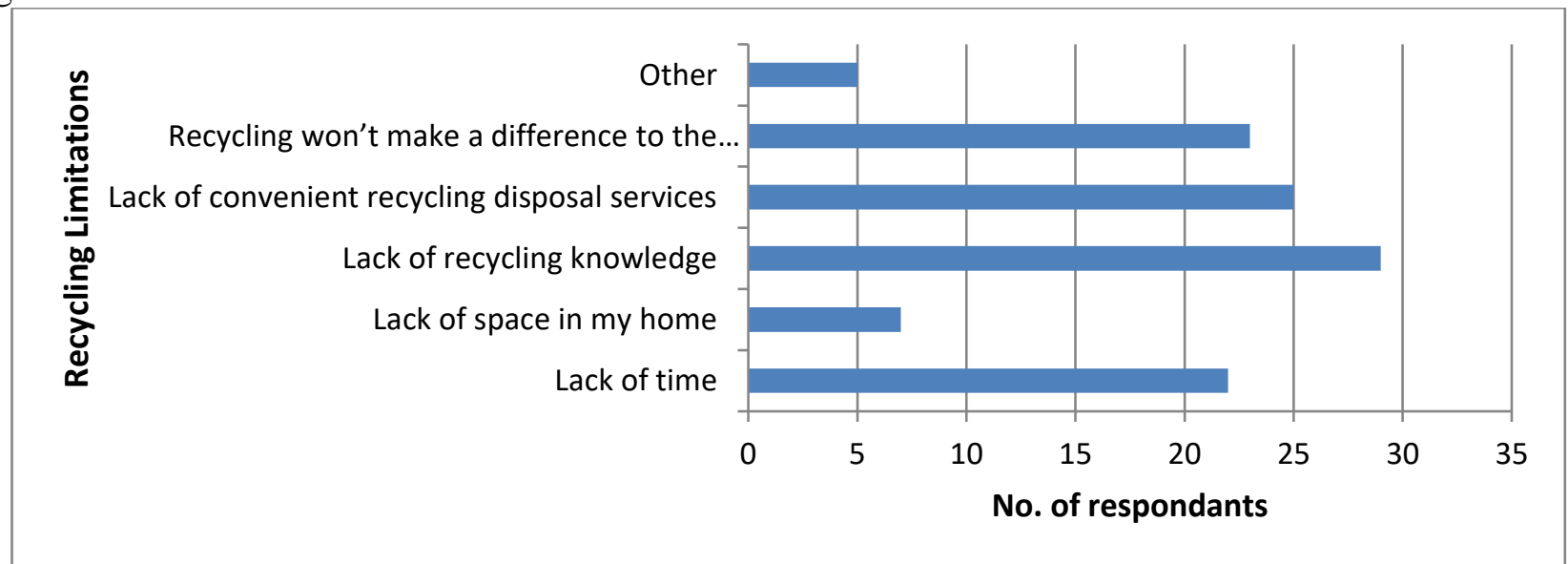

Figure 2: Bar graph representing the various limitations to recycling being experienced by non-recyclers of Upper Claremont. 
A municipal led recycling collection service would make recycling more convenient for households. A lack of convenient recycling services was a major limitation in why households do not recycle. It was assessed whether participants would support a municipal led recycling collection service. Both recyclers and non-recyclers responded to the question; a total of $74.5 \%$ felt that they would support a recycling collection service and $25.5 \%$ indicated that they are not interested. A lack of interest could pertain to a lack of education where people do not understand the importance of recycling and how one household can make a difference ${ }^{17}$. The vast majority of respondents who indicated that they were not interested in a recycling service were current non recyclers. Read [18], highlighted on the need for government participation in creating awareness on the people on the need for recycling of waste.

\section{Correlation Matrix}

The relationship that existed between household's interest in waste management and the individual recycling ability was examined using correlation analysis. According to the Pearson correlation, a significant and positive relations $(\mathrm{r}=$ $0.89, \mathrm{p}=0.0001)$ (significant level at $\mathrm{p}<0.05$ ) between the household's interest in waste management and the individual recycling ability. The reason behind this might be that the increase household's interest in waste management also increases the individual recycling ability.

In the linear regression between household's interest in waste management and the individual recycling ability indicated a linear model as described below:

$$
Y=2.3783 x+0.9193
$$

Where $\mathrm{Y}$ is the individual recycling ability and $\mathrm{X}$ is the household's interest in waste management (Figure 4).

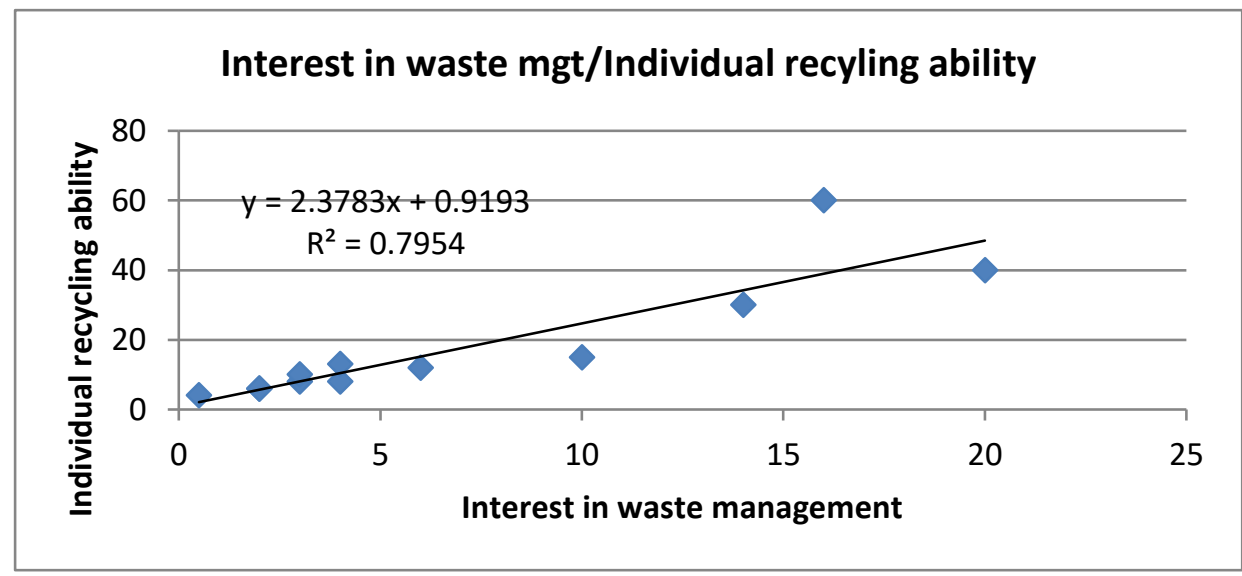

Figure 4: Linear regression between the household's interest in waste management and the individual recycling ability

\section{SWOT Analysis of Household Recycling}

Strengths: Increase in environmental awareness: most of respondents noted that waste should be recycled and that the municipality has to develop effective recycling points; habits that are transmitted to family members are underutilized as well as growth in environmental values (strive to manage waste).

Weaknesses: Lack of conditions (no accessible recycling points closer to the people, insufficiently developed recycling collection infrastructure); mistrust in the recycling system, its benefits and effectiveness (belief that waste recycled by an individual or household will not make a difference in the global waste generation); lack of information about benefits and importance of recycling and general waste management.

Opportunities: Development of a convenient recycling collection infrastructure; introduction of economic incentives (lower taxes for those who recycle); further awareness rise.

Threats: A developed infrastructure will not satisfy real needs; recycling may not become financially rewarding immediately; improper decisions about the waste management system and waste treatment practices from the government, when people do not see any real benefit of recycling; it will then discourage people from recycling. 


\section{Discussion}

Out of the $74.5 \%$ of participants who are interested in a recycling service, $65.5 \%$ of them are prepared to pay a minimal fee for the service. All but $10 \%$ of the respondents agreed for a recycling fee to be included in municipal rates and taxes. It is evident here that many households in Upper Claremont would be willing to change their recycling behaviour if convenient services were provided for by the Municipality, this is in accordance to the literature that eludated behaviour change as one of the factors that implements people's yield towards recycling and waste management in general [18]. About $12 \%$ of the respondents amongst those that do recycle consented to the establishment of recycling depot in Upper Claremont, as well as indicating a need for basic recycling education. This is an indication that only those that recycle that do want to recycle more, but less on those that do not [17,19]. The reason behind this indicator module is because knowledge and the idea of recycling tends to bring about the interest for such activity, hence making the people understand what impacts their interest and what does not especially in the case of recycling of wastes. The recycling scheme should focus on tackling two major limitations which a majority of households in Upper Claremont currently face; a lack of education and guidance, as well as a lack of recycling infrastructure and services. It was found that environmental awareness as well as attitude towards recycling largely predicted household recycling behaviour. Participants who felt a sense of responsibility towards conserving the environment were most likely to recycle. This call for a perception change where non recyclers need to be made aware that there is a link between recycling household waste and a global issue such as climate change $[7,13,15]$.

\section{Conclusion}

There were a number of limitations and boundaries identified by this study which effect household behaviour in Upper Claremont. With a growing global waste issue, landfills running out of space in Cape Town as well as present findings indicating that only $33 \%$ of households in Upper Claremont recycle household waste it is therefore recommended that the local municipality implement a recycling scheme to encourage pro-recycling behaviour.. Residents of Upper Claremont need to be educated with basic recycling knowledge including; how household waste is sent to a landfill, how the environment is effected if we do not recycle, what can/cannot be recycled, and how each household can make a difference to conserving the environment. Considering that children form a greater part of households in Upper Claremont with about $66.1 \%$, local schools are therefore a great platform for recycling education. Thus it is recommended that recycling education be taught in local schools around Upper Claremont by including recycling education as part of their curriculum or as an after school recycling club. Schools can encourage recycling by introducing a recycling day or recycling competitions. Children are an effective change tool as they can bring their enthusiasm home and teach their parents the importance of recycling. This study therefore, was able to provide behavioural change amongst the people in the area of the study.

\section{Acknowledgment}

The University of South Africa is highly appreciated for providing the space for this study.

\section{References}

[1] Akil, A.M. and F.C.S Ho, 2015. The Effects of Socio-Economic Influences on Households Recycling Behaviour in Iskandar Malaysia. Soc. Behav. Sci., 202: 124-134.

[2] Oasis Association. 2016. Employment Opportunities: http://www.oasisrecycling.co.za/Page.php?pageID=9 (accessed August 30, 2016).

[3] US Environmental Protection Agency. 2016. Recycling Basics. Available from: https://www.epa.gov/recycle/recycling-basics (assessed May 21, 2016).

[4] Robinson G \& Read A (2005). Recycling behaviour in a London Borough: Results from large-scale household survey. Resources, Conservation and Recycling 45: 70-83.

[5] Statistics South Africa. (2011). City of Cape Town Key Statistics. Available from: http://www.statssa.gov.za/?page_id=1021\&id=city-of-cape-town-municipality (assessed August 24, 2016)

[6] City of Cape Town. (2016). City of Cape Town Waste Review. Available from: https://www.capetown.gov.za/en/Solidwaste2/PublishingImages/Flyer_Waste_Review_Eng.pdf (accessed August 23, 2016)

[7] Oelofse, S. 2013. South Africa's Household Recycling Target. Available from: http://journals.co.za/content/CSIR (assessed May 21, 2016) 
[8] Latif, S. A., Omar, M. S. Bidin, Y. H., \& Awang, Z. (2012). Environmental Problems and Quality of Life: Situational Factor as a Predictor of Recycling Behaviour. Procedia - Social and Behavioral Sciences, 35(December 2011), 682688.

[9] Latif, S.A., M.S. Omar, Y.H. Bidin and Z. Awang, 2012. Environmental Values as a Predictor of Recycling Behaviour in Urban Areas: A Comparative Study. Procedia - Social and Behavioral Sciences, 50(July): 989-996.

[10] Bao, R. 2011. Waste and Recycling Attitudes and Behavior of Students in Turku. Master Thesis, University of Turku, Finland. pp, 20-24.

[11] Adomavičiūtė, T., J. Kruopienè, V. Varžinskas, and I. Gurauskienė, 2012. Waste Sorting Habits by the Community of Kaunas University of Technology, Reasons and Influencing Factors. Environ. Res. Eng. Man., 4: 57-67.

[12] Bortoleto, A.P. K.H. Kurisu and K. Hanaki, 2012. Model and Development for Household Waste Prevention Behaviour. Waste Man. 32: 2195-2207

[13] Bortoleto, A. P., Kurisu, K.H., Hanaki, K. (2012). Model and Development for Household Waste Prevention Behaviour. Waste Man., 32: 2195-2207

[14] Mtutu, P. and G. Thondhlana, 2015. Encouraging Pro-environmental Behaviour: Energy Use and Recycling at Rhodes University, South Africa. Hab. Intern. 53: 142-150.

[15] Mutang, J. and S. Haron, 2012. Factors Predicting recycling Behaviour among Malaysian. Southeast Asia Psych. J., 1: 68-80.

[16] Pakpour, A.H., I.M. Zeidi, M.M. Emamjomeh, S. Asefzadeh and H. Pearson. 2014. Household Waste Behaviours among a Community Sample in Iran: An Application of the Theory of Planned Behaviour. Waste Man. 34: 980 984.

[17] Mutang J \& Haron S (2012). Factors Predicting recycling Behaviour among Malaysian. Southeast Asia Psych J. 1: 68-80.

[18] Read, A. D. (2001). National Strategy, Local Practice and the Solid Waste Management Gap- A Local Authority Management Perspective on Sustainable Solid Waste Management. Unpublished PhD thesis. School of Geography, Kingston University, Kingston upon Thames: Surrey, UK. pp. 21-37.

[19] Tabernero, C. B. Hernandez, E. Cuadrado, B. Luque and C.R. Pereira, 2015. A Multilevel Perspective to Explain Recycling Behaviour in Communities. J.Environ. Man. 159: 192-201. 


\section{Summary Output}

\begin{tabular}{lr}
\hline \multicolumn{2}{c}{ Regression Statistics } \\
\hline Multiple R & 0.89188 \\
R Square & 0.795449 \\
Adjusted R Square & 0.774994 \\
Standard Error & 8.101448 \\
Observations & 12 \\
\hline
\end{tabular}

\begin{tabular}{|c|c|c|c|c|c|}
\hline & $d f$ & $S S$ & $M S$ & $F$ & $\begin{array}{c}\text { Significance } \\
F\end{array}$ \\
\hline Regression & 1 & 2552.332 & 2552.332 & 38.88766972 & $9.68 \mathrm{E}-05$ \\
\hline Residual & 10 & 656.3345 & 65.63345 & & \\
\hline Total & 11 & 3208.667 & & & \\
\hline
\end{tabular}

\begin{tabular}{|c|c|c|c|c|c|c|c|c|}
\hline & & Standard & & & & Upper & Lower & Upper \\
\hline & Coefficients & Error & t Stat & $P$-value & Lower $95 \%$ & $95 \%$ & $95.0 \%$ & $95.0 \%$ \\
\hline Intercept & 0.919341 & 3.561157 & 0.258158 & 0.801520412 & -7.01541 & 8.854094 & -7.01541 & 8.854094 \\
\hline interest in waste management & 2.378318 & 0.381385 & 6.235998 & $9.68 \mathrm{E}-05$ & 1.528539 & 3.228098 & 1.528539 & 3.228098 \\
\hline
\end{tabular}

